\title{
Growth of mixed cancer cell population - in silico the size matters*
}

\author{
Adam Kłóś⿴囗十 and Przemysław Mieszko Płonka® \\ Faculty of Biochemistry, Biophysics and Biotechnology, Jagiellonian University in Krakow, Kraków, Poland
}

\begin{abstract}
Cancer heterogeneity is still underexplored and difficult to investigate. The whole network of factors engaged in tumor growth makes clinical cases, as well as the in vivo and in vitro experiments, of limited use in terms of understanding cancer heterogeneity. Our idea was to start from scratch and focus on the simplest distinctive feature in a heterogeneous tumor, namely the cell size. To exclude any other factors, we created a rudimentary cellular automata model of mixed cancer culture with two lines of different cell sizes. We tested the model with various sets of parameters to explore how the cell size affects cancer co-culture growth. It turned out that the cell size plays a crucial role in in silico heterogeneous tumor growth. The dominance of bigger cells decreases the number of cells in the overall mixed cancer population. In contrast, the small cells increase the total number of cells, even without a parallel enlargement of the macroscopic tumor size. Predominance of the smaller cells is particularly visible under overcrowded conditions. Although our model was primarily designed for verification of experimental hypothesis and as a mean for better understanding of the cancer heterogeneity itself, it also has some practical value. Our findings can affect today's practice of estimating tumor growth based on its macroscopic size and may propose a new approach to interpreting histological data. After modifications, the model may serve to test other factors affecting growth of mixed populations of cancer cells differing in size.
\end{abstract}

Key words: cancer growth, cancer heterogeneity, cell size, cellular automata, co-culture, game of life

Received: 13 July, 2020; revised: 03 September, 2020; accepted: 22 September, 2020; available on-line: 26 November, 2020

『e-mail: adamklos5.16@gmail.com (AK); przemyslaw.plonka@ uj.edu.pl (PMP)

*Presented at the XLVII Winter School of the Faculty of Biochemistry, Biophysics and Biotechnology of the Jagiellonian University "Molecules, Pathways, and Games", February 8-12, 2020, Zakopane, Poland.

Acknowledgements of Financial Support: The Faculty of Biochemistry, Biophysics and Biotechnology of the Jagiellonian University in Kraków was a partner of the Leading National Research Center (KNOW) supported by the Polish Ministry of Science and Higher Education. The paper was partially supported from this grant (KNOW 35p/10/2015 to PMP).

Abbreviations: CA, cellular automata; GoL, game of life

\section{INTRODUCTION}

In 1971, the United States President, Richard Nixon, declared war against cancer (Sporn, 1996). Scientists from all over the world eagerly joined this fight. At that time, the strategy seemed to be simple: identify the enemy, target it, and destroy. During the past few decades, we have learned that this is not so simple. Due to cancer heterogeneity, a regular war turned into a guerrilla war, with enemies moving fast, changing their size, shapes, uniforms, and blending into normal cells. As the battlefield changes, it is of utmost importance to better understand the enemy, its strengths and weaknesses, its capabilities, mechanisms of action, and avoidance.

Tumor heterogeneity is an important reason why the early approach to cancer treatment failed in many respects (Burrell et al., 2013; Alizadeh et al., 2015). Most therapies have been focused on specific cancer cell lines, whereas the actual composition of a tumor keeps changing continuously. Clonal evolution (McGranahan \& Swanton, 2017) alters both, the genetic make-up (Turajlic et al., 2019) and the phenotype (Meacham \& Morrison, 2013) of the cancer cells. Moreover, mutual interaction between the tumor and its niche additionally contributes to the complexity of the erratic development of cancer (Junttila \& de Sauvage, 2013). All this makes the phenomenon of tumor heterogeneity very difficult to analyze, especially when one starts with cell populations resembling those observed in actual tumors. Thus, a well-controlled environment that allows one to observe the development of the cell heterogeneity from the very beginning is needed.

When starting to design a rudimentary model of a heterogeneous tumor, one has to establish a simple criterion of the heterogeneity. One of the simplest distinguishing features of a cell is its size. It is a well-known fact that the growth and the propagation of cancer vary depending on the cell size ( $\mathrm{Li} \&$ Lowengrub, 2014; Li et al., 2015; Schmoller, 2017), and that the size of the cells in a heterogeneous tumor differs (Sastre-Garau et al., 2004; Ruan et al., 2019; Xu et al., 2020). Therefore indeed, the cell size may be a good starting point for analyzing the cell population heterogeneity. One can think, for example, of creating a model of heterogeneous cancer population by making cells differing in size grow together.

Going into details, it is possible to create an in vivo or in vitro co-culture model composed of two cancer lines that differ in respect to their cell size. Interestingly, similar cases are found in nature in the form of collision and mixed tumors (Seifert \& Donath, 1996; Kroemer \& Perfettini, 2014; Michalinos et al., 2015; Saad et al., 2019). While this approach is promising, it still inherits all the disadvantages of heterogeneous tumor cell populations mentioned above. There is a limited control over the experimental environment. Moreover, the other interactions, besides cell size, must be engaged in such cases. As a result, the in vivo model consisting of two cell lines of different sizes is still hard to predict and impossible 
to control, which does not make the study of the heterogeneity any easier.

The co-culture growing in vitro has a better chance of success. Here the researcher can at least influence the experimental setup and control the environmental conditions. Unfortunately, to our knowledge, no such attempts of mixing in vitro two cancer cell lines differing in size were reported. There is still a possibility to mix the cells in vitro and to monitor their growth and metastasis in vivo (Steenbeek et al., 2018). However, even under such conditions the issue of the actual biological interactions remains unexplored.

The only model that can rule out the other factors and focus on the one chosen parameter controlling growth is the in silico model. As the geometry is particularly easy to model, this approach is especially predestined for simulating the effects of cell size. Consequently, the computer co-culture model of cell lines differing in size seems to be the natural choice for the simplest model of the heterogeneous cancer population.

The main question posted in this paper is whether the cell size influences the kinetics and pattern formation of a growing heterogeneous population in silico. To answer this question, the following objectives are defined. The primary goal of this study is to create an in silico model of a mixed cancer culture. The second step is to determine the model parameters, namely the appropriate lattice size for the simulations and the game of life rules required for modeling the cancer growth. The next and most important objective focuses on testing the model behavior with different parameter settings and estimating the influence of cell size on the mixed culture dynamics and its pattern. Finally, the model potential and its limitations are outlined in a kind of "SWOT" analysis. Simultaneously with this in silico study, complementary in vitro and in vivo experiments are conducted to be reported in future papers.

To create the in silico model, we chose the simple and well-established tool of cellular automata (CA) (Baer \& Martinez, 1974; Wolfram, 1986; Adamatzky, 2018). This is a popular tool used for cancer growth simulations (Shirinifard et al., 2009; Szabo \& Merks, 2013; Deutsch \& Dormann, 2017). In CA models, the behavior of cells inhabiting the fixed lattice is determined by the number of neighbors. These local interactions result in the emergence of a global pattern (Hadeler \& Müller, 2018). This feature ensures that the experimenters do not control the simulation but simply allow the growing cancer to self-regulate. Moreover, the CA, due to its nature, is particularly useful for visualization of geometry. Taking this into account, the CA model is suitable for creating an environment where the kinetics and pattern of the growing heterogeneous population is affected by the cell size only.

The elementary set up in CA is one cell occupying one site in the lattice. Therefore, most of the CA models assume that the cell size is constant with respect to one another, and to the lattice spacing. The problem of cell size in CA was indirectly addressed. Chen and Mynett (2003) compared how a variable cell size influences simulation. However, they did not mix cells differing in size, but only compared the output run on a different lattice spacing (Chen \& Mynett, 2003). Tzedakis et al. in one simulation used different lattices for cells and different lattices for nutrient and oxygen intake, yet the cancer cells stayed the same size (Tzedakis et al., 2014). Development of the CA method allowed for departure from originally rigid lattices. The lattice-gas cellular automata (LGCA), the complex automata model (CxA) or the cel- lular Potts models (CPM) gave, for instance, the possibility to change the cell size (Graner \& Glazier, 1992; Palmari et al., 1997; Wcisło et al., 2010). However, these changes usually are coupled with the cell cycle or the cell age and take place within pre-established limited ranges. Therefore, they do not relate to the entire population and do not allow for cell line differentiation. To fill this gap, we introduce the model that simulates the growth of two cancer cell lines on the same lattice. The cells in these lines can differ with respect to the cell size and the proliferation rate. The line-specific game of life rules may also be introduced, as well as the overall size of the initial population and the proportion of cells of the two lines. A proper manipulation of these parameters allows to explore in-depth the model boundaries and in different context determines how the cell size affects the behavior of the heterogeneous cancer cell population.

\section{MATERIALS AND METHODS}

Model. The mixed cancer culture model proposed in this paper is a two-dimensional cellular automata model with the local interaction based on the Moore-type configuration (Deutsch \& Moreira, 2002). The lattice spacing can be empty or occupied by a cancer cell. In our model, there are two types of cells, Line1 (red) and Line2 (blue). The fate of a cell depends on the number of neighbors of its own line, according to the implemented game of life $(\mathrm{GoL})$ rules, which are set independently for each cell line. The model is available in two versions, with cells of identical size or cells of different sizes. This paper primarily explores the model with cells of different sizes. The model with identical cells was only used for comparison in the section "The size of the initial population." The details regarding the model creation and its functionality can be found in the supplementary material. The program block diagram is presented in Fig. S1 (at https:/ / ojs.ptbioch.edu.pl/index.php/abp/) and the process of cell iterations is shown in Fig. S2 (at https://ojs. ptbioch.edu.pl/index.php/abp/).

The following adjustments to original CA game of life were introduced in the mixed cancer culture model: (1) two different populations of cells were introduced; (2) additional parameters for user customization were made available, namely: a) the size of lattice, b) the cell size (the cells can be identical, or can differ fourfold in size), c) the number of cells in the initial population, d) the Line1:Line 2 proportion in the initial population, e) the ratio of proliferation speeds, f) the rules of GoL; (3) the cell's state occurring with a given probability.

In addition, the model offers a possibility to evaluate various distributions of cells in the initial population: a random uniform placement, a clustered placement with a chosen number of centers per line (one center selected per group returns a compact distribution of cells) and two other cases of metastatic scenario, where one of the cell lines invades the other and vice versa. The panel presenting all of these possibilities is available in the supplementary material (see Fig. S3 at https://ojs.ptbioch. edu.pl/index.php/abp/). Each distribution is suited for a different purpose. The uniform distribution (supplementary video $1 \mathrm{~A}$ at https://ojs.ptbioch.edu.pl/index.php/ $\mathrm{abp} /$ ) reflects the situation of in vitro experiments with two cancer lines mixed ex vivo whereupon serving as an inoculum for a new co-culture. It also reflects the socalled "mixed tumors" in which several types of histologically different cancer cells grow uniformly distributed (see, e.g., Ohata, 2018; Kurimoto et al., 2020). Because 
this is the simplest setup and it simulates the first step in mixed cancer culture examination, uniform distribution was chosen for this introductory paper. Therefore, the cells of the initial population in all following experiments are evenly distributed all around the lattice. Clustered placement would be more appropriate for simulation of in vivo experiments, where the initial populations of cancer cells are usually more compact. Those well represent the so-called "collision tumors" (supplementary video $1 \mathrm{~B}$ and 1C at https://ojs.ptbioch.edu.pl/index.php/abp/) recently widely reported in numerous case studies (see e.g. Sterz et al., 2019; Hobbs et al., 2020; Mizuta et al., 2020). Finally, the last two cases (supplementary video $1 \mathrm{D}$ and $1 \mathrm{E}$ at https://ojs.ptbioch.edu.pl/index.php/ $\mathrm{abp} /$ ) being actually a special case of collision tumors (Bao et al., 2020) can model the rare instances where one type of cancer metastasizes to another tumor (Wong et al., 2017; Bao et al., 2020). As we analyze the cases of tumors differing in cell size, we show here the case (supplementary video 1D) when the tumor of smaller cells (Line2, blue) metastasizes to the tumor of bigger cells (Line1, red), and vice versa (supplementary video $1 \mathrm{E}$ at https:/ /ojs.ptbioch.edu.pl/index.php/abp/).

\section{Parameter setting.}

(a) The lattice size consists of sites that are all available for cancer cells to inhabit. Thus, a 10k size lattice offers 10,000 places that can be occupied by the smaller cells. The lattice is squared, so not all sizes are available, only those whose square root returns an integer. Therefore, the so-called "100k" lattice, in reality, has 99856 sites available. For the sake of clarity in this paper, we keep using the "100k" name. However, for all the calculations and data analysis, naturally, the accurate size was used.

In order to determine the size of lattice appropriate for experiments, the dependency between the lattice size and the model behavior was specified. Three lattices of different scales of $10 \mathrm{k}, 100 \mathrm{k}$, and $1000 \mathrm{k}$ were tested with simulations performed under standard conditions (see Table 1a). The results were analyzed as follows.

First, the visual examination of the simulation was performed to determine how changes in the lattice influence the visual pattern of the model. No visible differences were identified from the results (see supplementary material Fig. S4 at https://ojs.ptbioch.edu.pl/index.php/ $\mathrm{abp} /$ ).

Next, we compared the parameters of growth curves used for fitting the data. The data consist of the number of cells counted during each iteration of the in silico cancer growth. The output was fitted with the Gompertz function commonly used for describing cancer growth
(Gompertz, 1825; Bassukas \& Maurer-Schultze, 1988; Castro et al., 2003). This function is characterized by the " $a$ " parameter which is the upper asymptote (interpreted as the maximal size of the cell population or the maximal tumor size), the growth-rate coefficient - parameter " $k$ " which affects the slope of the function and the " $c$ " parameter indicating the time of inflection (see supplementary material Fig. S5 at https://ojs.ptbioch.edu.pl/index.php/abp/) (Tjørve \& Tjørve, 2017). The comparison of each growth curve parameters $(a, k, c)$ between matrices of $10 \mathrm{k}, 100 \mathrm{k}$, and $1000 \mathrm{k}$ showed no statistical differences (see supplementary material Table S1 at https:// ojs.ptbioch.edu.pl/index.php/abp/). The mathematical function describing cancer growth in these three scales remains the same.

Finally, the number of cells for each iteration was scaled and compared to others. So, at each step of the iteration, the population of cells growing on the $10 \mathrm{k}$ lattice was multiplied by 100 , on the $100 \mathrm{k}$ lattice was multiplied by 10 (exactly by 10.014) and the population raised on the $1000 \mathrm{k}$ lattice remained unchanged. The results presented in supplementary Fig. S6 (at https://ojs.ptbioch.edu.pl/index.php/abp/) show that the data overlap within the statistical error.

Either the visual examination, the comparison of the growth curve parameters, or the scaling test ensure that the mixed culture model is insensitive to changes in the lattice size and can be linearly scalable. A minor derogation was observed for simulations run on the 10k lattice, which indicates that using lattices of smaller size may be problematic. Therefore, for the experiments presented in this paper, the optimal size of $100 \mathrm{k}$ was chosen. The advantage of this choice is the low computational power required for such simulation without loss of precision.

(b) The cell size in the mixed culture model differs, i.e., the cells of Line1 (red) are four-times bigger than these of Line 2 (blue). In the second version of this program, the cells of Line1 and Line 2 are of the same size, yet still differ in terms of other parameters.

(c) The size of the initial population in the paper is given in total (as the sum of cells from both lines) and, if not mentioned otherwise, is set at $2.5 \mathrm{k}$. For the size of $2.5 \mathrm{k}$, for example, there are 1250 cells of Line1 and 1250 cells of Line 2 at the beginning of the simulation.

(d) Line1:Line2 proportion determines the distribution of cells in the initial population. With one exception (see section "The Line1:Line2 proportion in the initial population"), the simulations were set out with an equal number of Line1 and Line 2 cells. This point aims to test how the distribution between Line1 and Line 2 cells influences the resultant cell growth. For instance, the pro-

\section{Table 1. The game of life rules.}

(a) The standard GoL rules aim to mimic cancer growth. These rules were used for experiments carried out in this paper unless explicitly was stated otherwise. (b) "Conway," the GoL rules, originally proposed by John Conway (Gardner, 1970). (c) The "maximum growth" rules that allow for the maximum growth of cell cancer lines.

\begin{tabular}{|c|c|c|c|c|c|c|c|}
\hline \multicolumn{2}{|l|}{ GoL rules: } & \multicolumn{2}{|c|}{ (a) standard } & \multicolumn{2}{|c|}{ (b) Conway } & \multicolumn{2}{|c|}{ (c) maximum growth } \\
\hline state & cause & probability & $\begin{array}{l}\text { number of } \\
\text { neighbors }\end{array}$ & probability & $\begin{array}{l}\text { number of } \\
\text { neighbors }\end{array}$ & probability & $\begin{array}{l}\text { number of } \\
\text { neighbors }\end{array}$ \\
\hline \multirow{2}{*}{ cell dies } & of loneliness & 0.1 & {$[0,1]$} & 1 & {$[0,1]$} & 0 & {$[0,1]$} \\
\hline & from overpopulation & 0.5 & {$[7,8]$} & 1 & {$[4,8]$} & 0 & {$[7,8]$} \\
\hline cell stays alive & & 1 & {$[2,6]$} & 1 & {$[2,3]$} & 1 & {$[2,6]$} \\
\hline \multirow{3}{*}{ cell is born } & range 1 of potential parents: & 0.25 & {$[1,2]$} & 0 & {$[1,2]$} & 1 & {$[1,2]$} \\
\hline & range 2 of potential parents: & 0.75 & {$[3,6]$} & 1 & {$[3,3]$} & 1 & {$[3,6]$} \\
\hline & range 3 of potential parents: & 0.9 & {$[7,8]$} & 0 & {$[4,8]$} & 1 & {$[7,8]$} \\
\hline
\end{tabular}


portion of 3:1 means that in the initial population, there were three times more cells of Line1 than cells of Line2. Numerically, for the initial population of $2.5 \mathrm{k}$, it would be 1875 cells of Line1 and 625 cells of Line2.

(e) The proliferation rate is set for each cell line separately, and it controls how fast the line is growing. Depending on the difference between proliferation rates $(\Delta p)$ of both lines, additional iterations for Line1 or Line2 can be granted (see supplementary material Fig. S1 at https://ojs.ptbioch.edu.pl/index.php/abp/). The $\Delta p$ parameter is a result of subtraction of the proliferation rates value of Line2 from Line1. Thus, if $\Delta p$ is less than zero, extra iteration is added to Line2, if $\Delta p$ is greater than 1 , the extra iteration is granted to Line1. In practice, if the proliferation rate of Line1 is 0.3 and Line2 is 1 , for each iteration of Line1 there will be three iterations of Line2. With the exception of section "The proliferation rate of cell lines" this proliferation rate is set at 1 for both lines.

(f) The GoL rules are set independently for Line1 and Line2. For these experiments, however, the rules were kept identical. Compliance with this condition allows us to set the baseline for testing other parameters. When defining the GoL rules, a user can freely decide at what number of neighbors (in the Moore configuration) the cell is born (divides) and when it stays alive. If the number of neighbors is not sufficient, the cell can die out of "loneliness," but, on the other hand, when too many neighbors accompany the cell, it dies from overpopulation. Also, the occurrence of these states came with user-defined probability. To gain more control over the model, three probability thresholds are introduced for cell birth and two thresholds for cell death.

The original game of life was defined by John Conway (Gardner, 1970; Adamatzky, 2010). This British mathematician rediscovered a tool introduced earlier by Stanislaw Ulam. For Ulam, the cellular automata were envisioned as a model of the computational machine (Neumann \& Burks, 1966) and, as such, gained quite an advanced level of sophistication. In the hand of Conway, initially complex CA turned into a simple three-states cellular game ruled by straightforward rules (Table $1 \mathrm{~b}$ ). This change helped to popularize CA and introduce it to the broad public. Therefore, Conway's GoL rules were the starting point also for our experiments. Unfortunately, the acceptance of the Conway's game of life rules leads very quickly to the drastic downfall of the cell population. At some point, the simulation is stabilized, and further growth is impossible. The collapse of the population at the first steps of iterations is caused by the rule of cellular death, i.e., the cell without a neighbor or with only one adjacent cell dies, whereas the condition that only cells with two or three neighbors stay alive prevents further growth of the co-culture. Therefore, the Conway GoL rules are unsuitable for modeling the dynamics of cancer growth. The rules have to be modified in a way to meet this criterion. In this paper, we propose two examples of such changes, the so-called "maximum growth" (Table 1c) and the "standard" rules (Table 1a). The first one allows cells to proliferate every time a free site is available in the neighborhood and completely excludes the possibility of cell death. In contrast, the "standard" GoL rules (see Table 1a) are intended to be closer to real-life cancer behavior. These rules adjust the probability of occupying a free place according to the number of neighbors. In addition, they allow cells to die from overpopulation (necrotic effect) and very rarely from loneliness (when deprived of communication with other cells). The probabilities associated with the occur- rence of these states were chosen with the trial-and-error method in such a way as to reflect the inner logic of biological phenomena. Therefore, as a number of potential parents around a free site grows, so does the probability of a new cell to be born there. In a highly compact environment, the odds for a cell to survive are 0.5 , and because cancer cells usually do not need reinforcement from other cells to grow and survive, the probability of death caused by loneliness is only 0.1 .

Simulations performed under maximum growth or standard rules with high accuracy (R-square 0.999) are fitted to the Gompertz function (see supplementary material Fig. S8 at https://ojs.ptbioch.edu.pl/index.php/ $\mathrm{abp} /$ ). This strongly suggests that a mixed cancer model with these rules is suitable for simulating cancer growth. The robustness of this model was tested with the Sobol method of global sensitivity analysis. The results indicate that the " $a$ " parameter of the Gompertz function (i.e., the maximal tumor size) plays a crucial role in the model's performance, and there are no evident interactions between parameters. For further details see supplementary material point 5 .

Data analysis. Each scenario examined was repeated ten times, which means that every point of data used for further analysis is an average of ten simulation outcomes obtained at a given iteration step. The error bars shown on the plots relate to the standard deviations for these ten outcomes. In cases of a visual examination of pattern formation (Figs. 1, 2, 7), the graphs result from a singular, exemplary simulation.

The code of mixed cancer culture was written in Python 3.7.3, and it was run on Anaconda 4.8.2 distribution on Mac Pro (late 2013) computer. For the fitting procedure, as well as the data analysis and visualization, the Origin Pro program was used. The source code of the mixed cancer culture model used to run experiments reported in this study is available at https://github.com/ complexitylab/mixedsizecancer.

\section{RESULTS AND DISCUSSION}

With the lattice size of $100 \mathrm{k}$ and standard GoL rules, the model was explored with different parameter settings. First, the influence of the initial population size on the mixed culture was examined. Next, the role of the cell size in the model dynamics was investigated. By dynamics, we simply mean the changes in the cancer population over time. It applies both, to the overall population and to the transformations that happen within particular cell lines. Further, the proliferation rate and different proportions of cancer lines in the initial population were explored. Finally, the effect of overcrowding was analyzed.

\section{The size of the initial population}

In nature, cancer usually begins with a single corrupted cell that takes the phenotype of an embryonic cell and the ability to proliferate, thus giving rise to the whole cancer population (Greaves \& Maley, 2012). However, in laboratory, this process is almost never replicated. In vitro or in vivo, experiments begin with the inocula of thousands of cancer cells, the spheroid, or the tumor tissue slice. These means of cancer inoculation are used for practical reasons. They are easier to operate and more effective. Still, in the beginning, one introduces not a single cell, but an initial population of cancer cells. Therefore, the question is whether the size of that initial population matters? In order to determine the influ- 


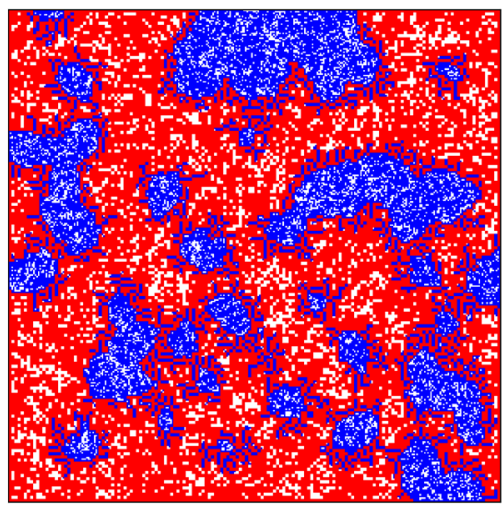

(a)

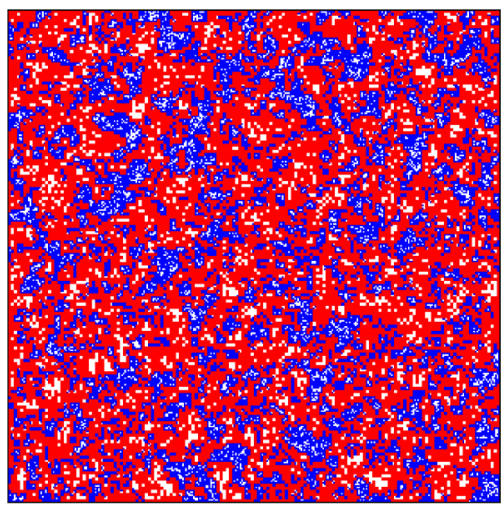

(b)

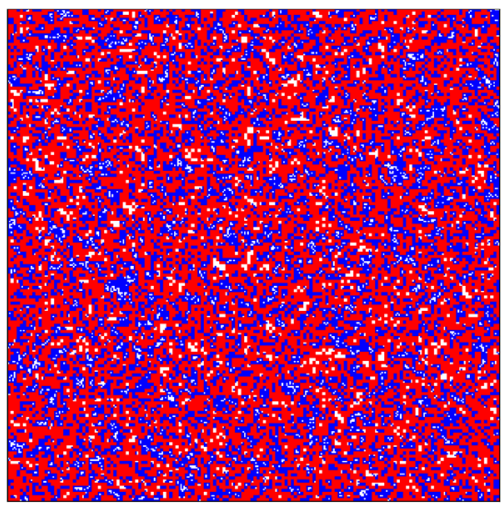

(c)

Figure 1. The disperse-lobular transition in tumor meshwork pattern.

The figures capture the advanced stage of simulations that start from the initial population of the size of (a) $0.1 \mathrm{k}$, (b) $2.5 \mathrm{k}$, (c) $12.5 \mathrm{k}$. These simulations are run for the mixed culture of different cell sizes. The bigger cells (Line1) are in red and the smaller ones (Line2) in blue. The cell number of Line1 and Line2 in the initial populations was equal. The figures show that the small size of the initial population leads to lobular morphology.

ence of the size of the initial population on the model dynamics, four sets of simulations with $0.1 \mathrm{k}, 0.5 \mathrm{k}, 2.5 \mathrm{k}$, and $12.5 \mathrm{k}$ initial populations were run. The output data were fitted to the Gompertz function. The results indicate a non-linear relation between the model kinetics and the size of the initial population. For details, see supplementary material point 6 .

Next, the influence of the size of the initial population on the model "morphology" (i.e., the overall pattern created by the mixed cancer cell population) was examined. Figure 1 shows the cell arrangement for simulations starting from $0.1 \mathrm{k}, 2.5 \mathrm{k}$, and $12.5 \mathrm{k}$ cells. An interesting phenomenon was observed for the smallest size of the initial population (Fig. 1a). If the populations of Line1 and Line2 start from 50 cells each, simulation tends to form a lobular pattern. This pattern seems to be common for the identical cell size model and the model where Line1 has bigger cells. In both cases, the lobular pattern emerges, although with some variations (Fig. 2). The simulation with identical cells forms a more connected and consolidated pattern, whereas in the case of different cell sizes the lobular pattern is more detached and jagged. One can imagine these features as being easily utilized for cancer characteristics by rapidly developing computer vision analysis. The very dynamics of these patterns' formation is better visualized in the supplement

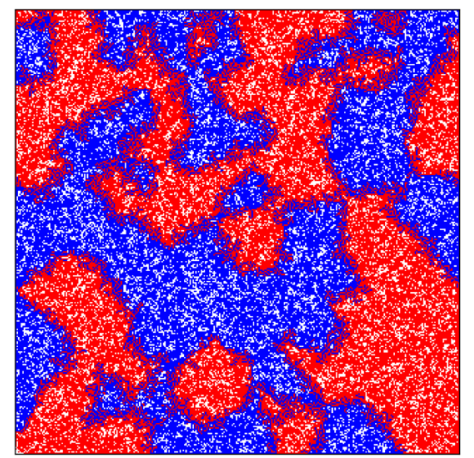

(a) material video at https://ojs.ptbioch.edu.pl/index.php/ $\mathrm{abp} /$ (part 3 and 4).

\section{The cell size}

The presented model exists in two versions. The first introduces the two lines of cells equal in size but with different other characteristics. The second operates on cell lines that also differ according to cell size. The following in silico experiment was performed in order to determine how the cell size affects such mixed cultures. The results are summarized in Fig. 3. The population of the bigger cells in mixed culture covers a larger area (Fig. 3a), yet it ends up with a lower number of cells (Fig. 3c). The opposite is true for the line with smaller cells. The smaller cells may occupy a minor part of the lattices, yet quickly outnumber the population of the bigger cells. This somehow surprising conclusion is not hard to explain. In the early steps of simulation, cells of both lines proliferate in an unobstructed way. However, as the lattice becomes filled, the bigger cells encounter increasing difficulties finding enough free place to replicate. This is not an issue for the smaller cells. Even if Line1 is jam-packed and stops reproducing, the cells of Line2 can still find enough place to proliferate and fill the places between the bigger cells. Looking from the perspective of the mixed culture, presence of the bigger

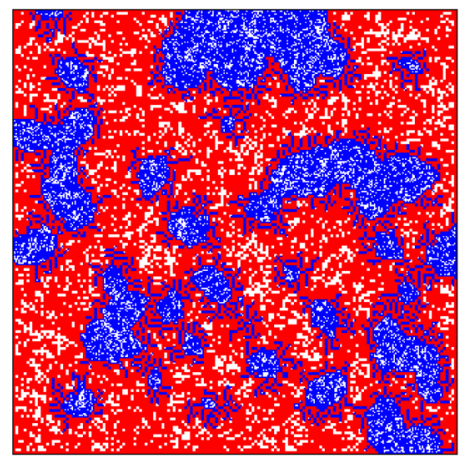

(b)

Figure 2. The lobular meshwork pattern of mixed culture of:

(a) identical, (b) different cell sizes. The cells of Line1 are in red, and these of Line2 in blue. Both simulations start from the initial population of $2.5 \mathrm{k}$ and equal proportion of Line1:Line2. Regardless of whether there are differences in cell size between cell lines (b), or not (a), simulations create a lobular morphology of a mixed culture. 

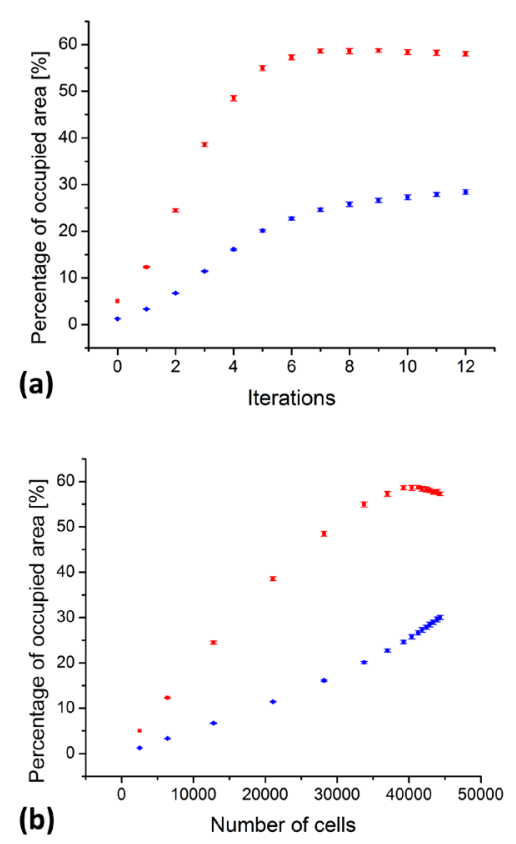

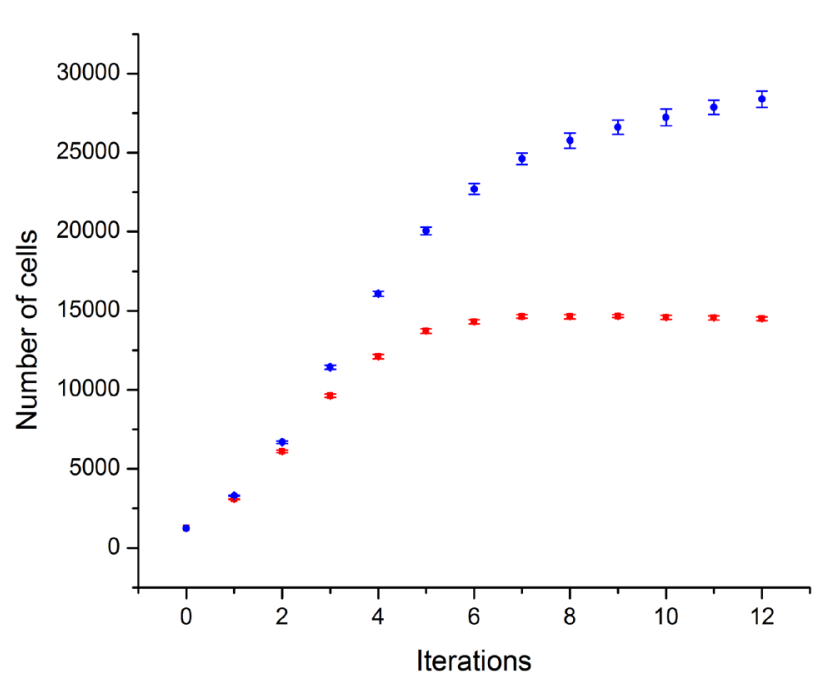

(c)

Figure 3. The influence of cell size on simulation of the mixed population growth dynamics.

The red squares represent the bigger cells of Line1, the blue circles the smaller cells of Line2. Panels display (a) the area occupied by mixed culture; (b) the occupied area versus the population size; (c) the population of mixed culture (total cell number). The overall conclusion is that the smaller cells in limited area proliferate in a higher number than the bigger ones.

cells respectively reduces the overall population of this culture expressed as the total cell number.

If the cell size has indeed such a great influence on the final population of the mixed culture, this should lead to interesting practical consequences. Firstly, not all niches are equally good for all kinds of cells. The smaller cells have the advantage of inhabiting the spaces (in 2D - the areas) unsuitable (due to the size) for the larger cells. Secondly, this outcome may somehow question today's practice (Talkington \& Durrett, 2015; Förnvik et al., 2016). Namely, in the case of the heterogeneous population (and most of the tumors should be considered as such), it turns out that it is not so easy to characterize cancer based on macroscopic tumor size. According to our results, the bigger cells may occupy the larger area, yet their population can be low, whereas the clones of smaller cells in a relatively cramped volume can outnumber the bigger cells.

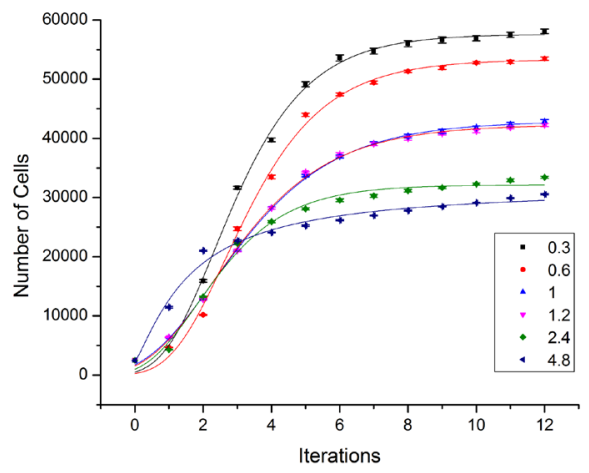

(a)
Therefore, not necessarily the most "visible" line is the most numerous one. Surprisingly, such an undervalued parameter as cell size may play a crucial role in cancer growth and propagation.

\section{The proliferation rate of cell lines}

Another parameter taken into consideration was the level of cellular proliferation. The model containing different cell sizes was tested with a set of proliferation rates. To expose the difference between lines, the proliferation value of Line1 (red, bigger) was changed, whereas the proliferation rate for Line2 (blue, smaller) stayed at 1 . Other settings for both lines remained identical (100k lattice, standard GoL rules, and initial population of $2.5 \mathrm{k}$ equally distributed between Line1 and Line2).

The results (Fig. 4) allow one to draw the following conclusion: the higher the proliferation rate of the bigger

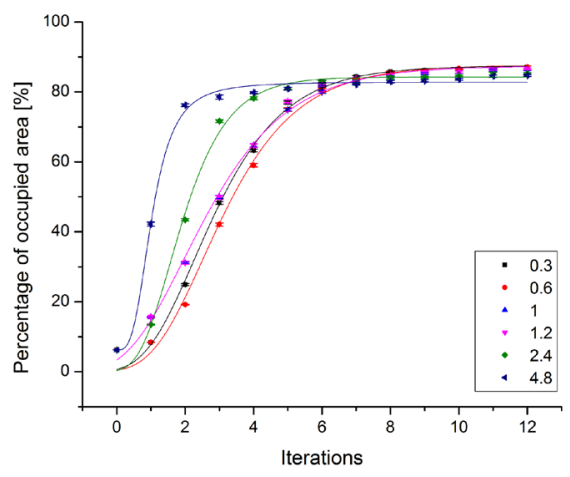

(b)

Figure 4. The relation between proliferation rates and resultant mixed culture growth.

The figures show (a) the population size (total number of cells) and (b) the area occupied by mixed culture with different proliferation rates of Line1 (the proliferation rate for Line2 stayed at 1). Higher proliferation rate of the bigger cells causes a decrease of mixed culture population and acceleration of lattice filling. 


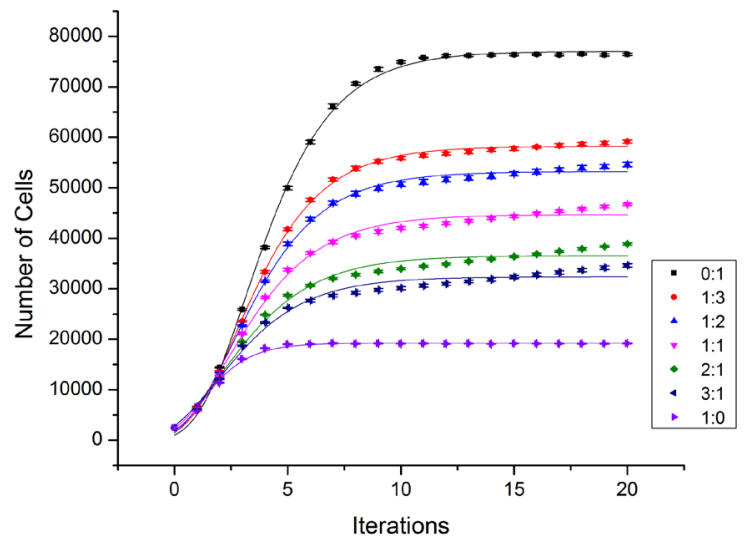

(a)

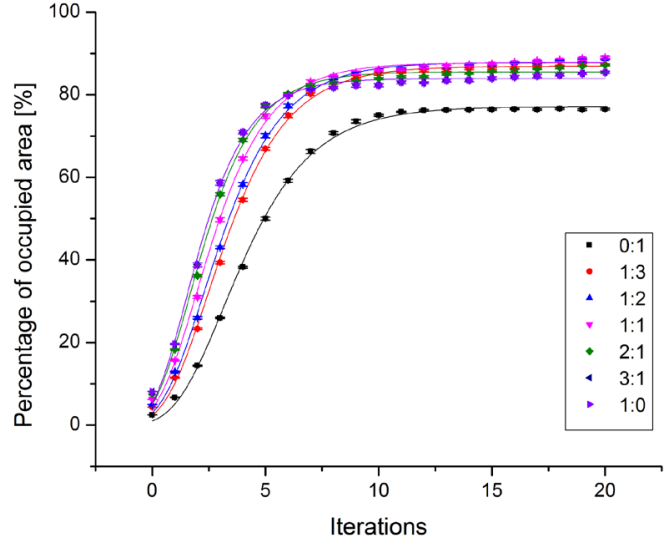

(b)

Figure 5. The growth of mixed culture with different initial Line1:Line2 proportions.

The graph shows simulation of mixed culture growth with different (0:1, 1:3, 1:2, 1:1, 2:1, 3:1, 1:0) proportion of Line1 (bigger cells):Line2 (smaller cells) in the inoculum. Figure displays (a) the growth curve of mixed culture; (b) the percentage of area filling. The results confirm that the higher the quantity of the bigger cell in the initial population, the smaller the number of cells in the final population of mixed culture and the faster the cancer growth in respect to its volume.

cells, the smaller the total cell number of the final population of mixed culture (Fig. 4a). Additionally, increasing the proliferation rate of Line1 results in accelerated lattice filling (Fig. 4b).

The take-home message that the higher proliferation rate of one cancer cell line can actually reduce the overall cancer population is again counterintuitive. The lesson to be learned from this outcome is that the proliferation rate should be considered in estimating the aggressiveness of a heterogeneous tumor only in pair with the cell size. Further, an even more important message is that the highest proliferation of cancer clones does not translate automatically into the most numerous population of the tumor.

\section{The Line1:Line2 proportion in the initial population}

One of the features that can be freely modified in the mixed culture model is the proportion of different cells in the initial population. How this parameter influences the behavior of the model is shown in this paragraph. Seven different proportions of Line1:Line2 were tested, and their impact on the model kinetics is presented in Fig. 5. A higher amount of the bigger cells in the initial population entails a reduction of the mixed culture population (expressed as the total number of cells) while, at the same time, it accelerates the growth of cancer with respect to the occupied area. A small derogation from the second rule is observed for an overcrowded lattice, which will be addressed in the next paragraph.

The presented outcome results described in the two preceding sections taken together allow one to conclude that the cell size along with the corresponding parameters that alter the proportion of different cell sizes in a mixed culture (e.g., the proliferation rate, the number and proportion of cell lines in the initial population) strongly affect the dynamics of a mixed culture. This determines the rate of cancer spread, how numerous its population is, and the contribution of particular cell lines in this process. This conclusion entitles one to emphasize that the cell size is an important factor when analyzing the growth and metastasis of heterogeneous cancer cell populations.

\section{The effect of overcrowding}

The last series of experiments were taken to determine the model behavior under overcrowded conditions. The collection of the data presented so far always stopped around $80 \%$ of the lattice filling. The experiments described in the present section allowed simulations to run beyond this point and cover the maximum lattice area possible. The experiments were done under the standard and maximum growth rules of GoL with 100k lattice and $2.5 \mathrm{k}$ size of the initial population. The results are shown in Fig. 6. As expected, at the lower level of lattice infilling, the simulation optimized for maximum cell growth outnumbered the population with the standard GoL rules. The situation changes as the lattice becomes overcrowded. At that point, the population of maximum growth reaches its upper limit and does not evolve anymore, whereas the population with standard GoL rules keeps growing (Fig. 6a). Further development of the standard population is due to the smaller cells that also keep reproducing under high-density conditions (Fig. 6b). The explanation of this fact lies in the adopted GoL rules. The maximum growth rules do not allow for cell death, so the simulation quickly progresses to occupy $100 \%$ of the area available and remains unchanged (Fig. 6c). In the case of the standard GoL rules, for each iteration, some cells die. As a result of that, the mixed culture never fully occupies the lattice, merely exceeding $80 \%$ of the lattice infilling (Fig. 6c). The constant cycle of cell death and birth, in turn, initiates the alteration of the mixed culture population. The sites freed from the bigger cells are gradually taken up by the smaller ones. Similarly, the space that is still inhabited, yet due to its size unsuitable for the cells of Line1, becomes occupied by the smaller cells (Fig. 6d). These factors explain the continued growth in Line2 population even after the lattice fulfillment. It is worth mentioning that the main factor in the described process is cell death caused by overpopulation. Another cause of cell death, i.e., loneliness, occurs very rarely and does not affect this simulation significantly. Also note that the GoL rules apply only within the same cell line, so the neighbors from the other line do not count.

Additional confirmation for the process described above came from visual examination. Figure 7 shows the 


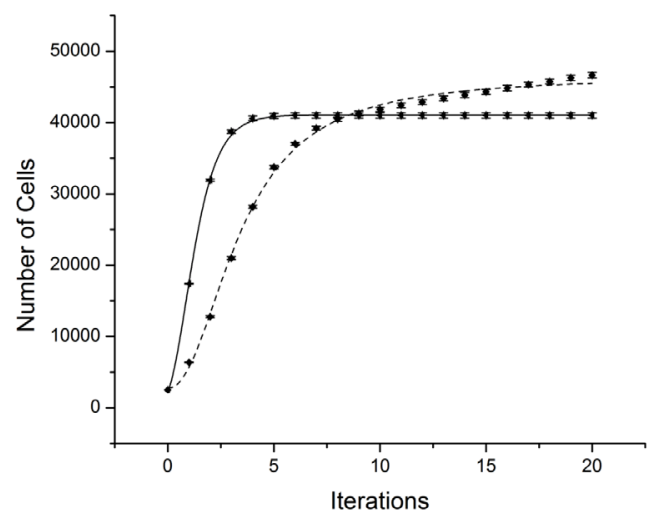

(a)

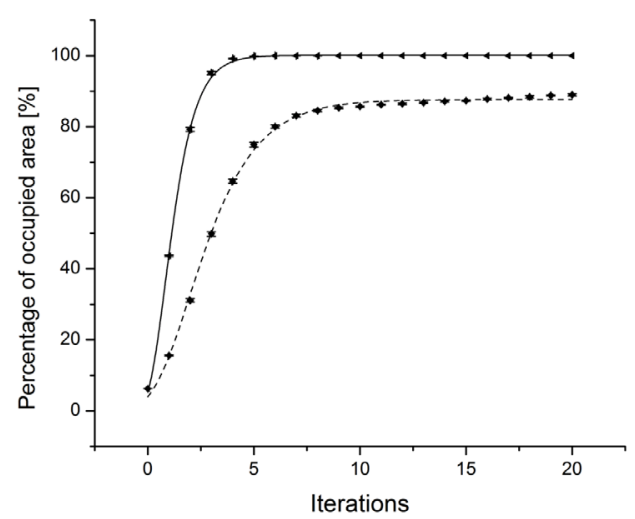

(c)

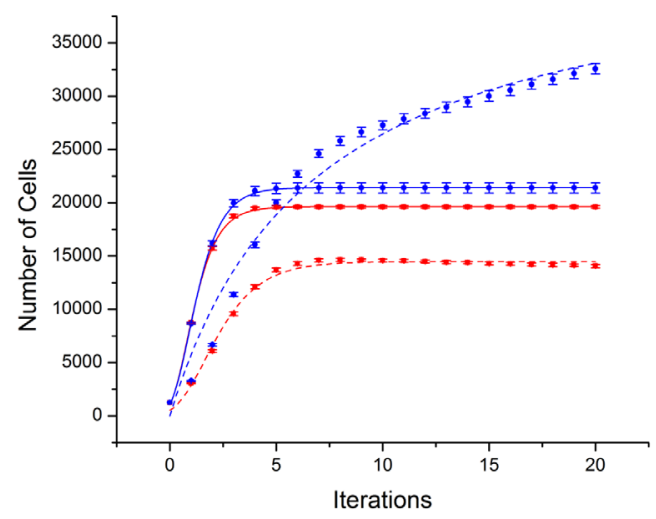

(b)

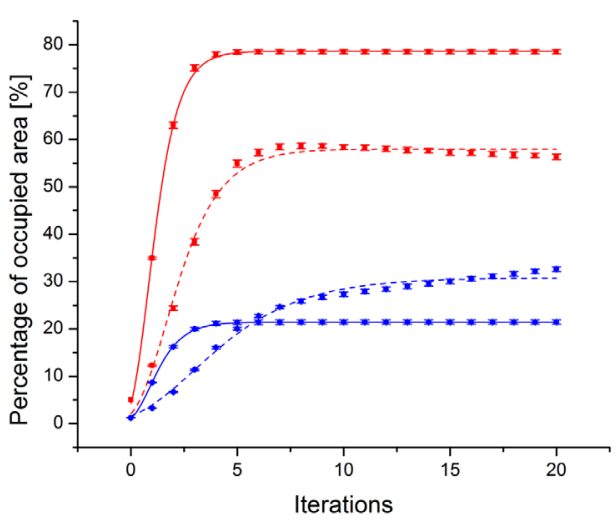

(d)

Figure 6. Simulation under overcrowding conditions.

The overgrowth of the mixed culture population for standard and maximum growth rules for (a) the overall population, (b) particular cell lines. The percentage of area occupied by mixed culture for (c) the overall population, (d) particular cell lines. The simulations run under standard GoL rules are visualized with dashed lines and under the maximum growth rules - with a solid line. The black lines represent the overall cell population, whereas the red lines with squares visualize the population of bigger cells (Line1) and the blue lines with circles - smaller cells (Line2). The figures show that the number of the smaller cells keeps growing, even after the lattice filling, and with them, the whole population increases.
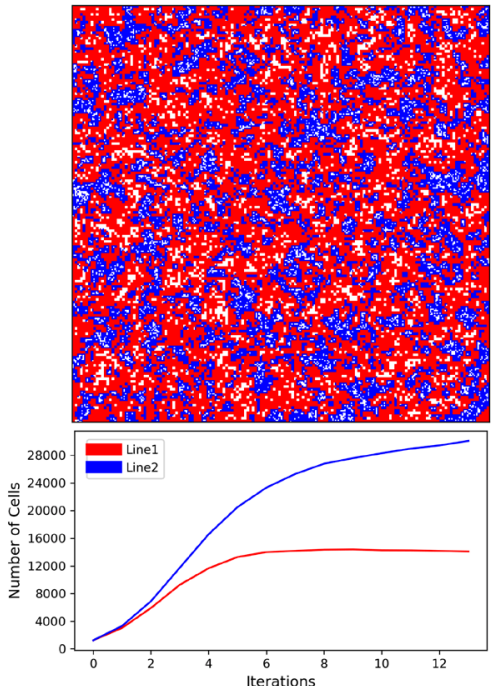

(a)
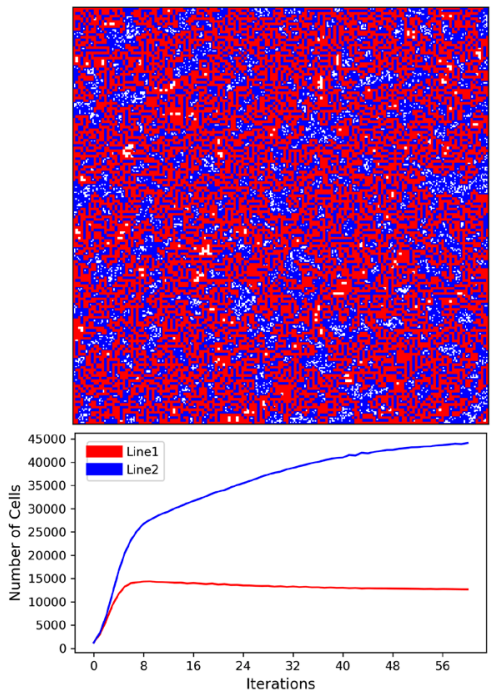

(b)
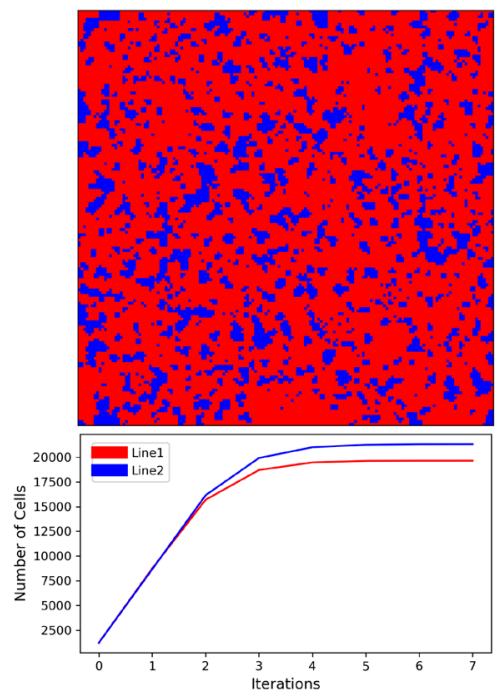

(c)

Figure 7. Meshwork pattern of tumors in mixed culture under overcrowded conditions.

Panels display (a) the standard GoL rules, simulation after 12 iterations; (b) the standard GoL rules, simulation in overcrowded conditions; (c) the rules of maximum growth. The figure shows evident pattern changes in an overcrowded environment for the standard GoL rules that allow for cell death (b) and maximum growth rules that exclude the necrotic effect (c). 
difference between overcrowded simulation under standard and maximum growth GoL rules. The standard rules that allow for constant population changes end up with a more homogeneous arrangement where the cells of Line1 and Line2 are evenly distributed (Fig. 7b). In contrast, the maximum cell growth rule forms a more segregated pattern where the cells prefer the company of their kind over the mixed environment (Fig. 7c). The process of penetration of the area occupied by the bigger cells by the smaller ones is much better visualized by the video submitted in the supplementary material (part 5).

The fact that under overcrowded conditions the mixed culture population undergoes systematic changes may have far-reaching consequences. Let us note first that the described situation is not unusual. The squeezed and tightly packed cells are the norm in a tumor, rather than an exception (Park et al., 2016). Secondly, necrotic cell death is a well-known process in every mature tumor (Karsch-Bluman et al., 2019). Thirdly, one can safely assume that most of the tumors, due to clonal evolution, are heterogeneous, and some of them can develop phenotypic profiles of different cell sizes (Wu et al., 2015, Kiuru et al., 2018). Therefore, it is not unreasonable to suspect that the process described above can happen in real life. From a practical perspective, as an evolution of a heterogeneous tumor progresses, the pressure may occur in favor of the cancer clones with smaller cell sizes (Hannig et al., 2020). Such a tumor, even without significant increments in magnitude, can still extend the size (numerical amount) of its population, and so may become increasingly aggressive (Asioli et al., 2014) and more metastatic.

\section{"SWOT" analysis}

One of the working goals of this paper is to put forwards the in silico model of growth of a population of cancer cells differing in size. As the factual results of particular simulations have been discussed in the previous sections, here we summarize them in the concise form of a "SWOT" (strengths, weaknesses, opportunities, threats) analysis.

\section{Strengths}

The tumor heterogeneity regarding the cell size is often the result of action of other factors creating the variability in size. By examining such a population, one cannot be sure that an effect is brought about by the size itself, or by the primary factors causing the size heterogeneity. Simultaneously simulating two lines differing in respect to the cell size, with the absence of any other factors, leads to some findings that otherwise would not be disclosed or would be lost in the details of complex models. Despite the model simplicity, a proper parameter setting allows it to imitate the cancer growth according to the Gompertz function. Customization of the program is its next advantage. The model supports GoL rules modification with user-defined probability. The proliferation rate with the basic choice of two cell sizes in accordance with the other parameters are available for modification. Finally, the economic and ethical aspects of this model should be marked, saving time, money, preventing thousands of animals from testing in details numerous combinations of parameters so as to formulate the best one to test in vivo.

\section{Weaknesses}

The main strength of the model is, at the same time, its major weakness. As this model is very simplified, it lacks many features commonly occurring in other biologically oriented CA models. In the mixed culture model, only the phenomena of cell death and mitosis are implemented, leaving behind the other important mechanisms affecting tumor growth. Alternative states of the cell cycle (like quiescent cells/resting cells state) are not introduced (Monteagudo \& Santos, 2015), nor the immunology response (Alemani et al., 2012), nor the effects of the other, non-cancerous cells (fibroblasts) (Picco et al., 2017). The nutrients' uptakes (BunimovichMendrazitsky et al., 2015), cellular motility (Kumar et al., 2016), adhesion, tissue pressure, cellular metabolism (Ascolani \& Liò, 2019), chemotaxis and hypotaxis (Tzedakis et al., 2015), tissue vascularity (Wcisło et al., 2009), and other factors are also omitted. However, what causes the greatest uncertainty is the lack of the experimental data that could support our findings.

\section{Opportunities}

The results presented in this paper open up some interesting opportunities. For example, the histological patterns of cancer growth can be used to quantify the initial metastatic population or to distinguish cell lines in the tumor. The findings may also influence the tumor diagnosis, forcing it to reconsider the cell size as an important factor in estimation of cancer aggressiveness (Kiuru et al., 2018). The temporary custom of expressing tumor growth by increasing its macroscopic size (volume) seems to be not valid anymore as the tumor cells may still proliferate without increasing the tumor size, which has been proven in the above simulations. Besides that, the model can be further explored with different sets of GoL rules, additional parameters, and new variables. Also, the other functions of cancer growth (than those given by Gompertz) may be tested and the additional determinants associated with the intercellular contact as well as the cell motility could be introduced into the model (see Matsiaka et al., 2019; Malik et al., 2020). Further development of the model could allow for more variety in choosing the cell size, as well as for introducing additional cell lines to a heterogeneous tumor. Empirical data confirm that heterogeneous tumors indeed consist of various cells (Al-Brahim \& Salama, 2005; Gerlinger et al., 2012; Stanta \& Bonin, 2018), and that the cell size is important in cancer growth and propagation (Grichnik et al., 2006; Rosai, 2011; Lyons et al., 2016). Our model can help to explain that the cell size, in addition to other e.g., mechanical parameters (Sarna et al., 2018), may give the answer. Finally, the model may be useful for clinical application primarily as an aid in data interpretation and for ruling out some research hypotheses.

\section{Threats}

Concerning the threats assessment for application of this model, there is a temptation to substitute the in vivo experiments with cheaper and less ethically dubious in silico experiments. This is a risky road (Mitchell, 2019), for which we are not, and perhaps never will be ready. This is why the authors emphasize the need for the wet lab experiments accompanying this study and are engaged in carrying them. The present model may only suggest some solutions or hypotheses otherwise difficult to establish.

\section{CONCLUSIONS}

In this paper, we presented a $2 \mathrm{D}$ cellular automata model of a mixed cell culture. The model introduces two 
separate cancer cell lines that can differ in respect of cell size. The following main findings can be mentioned: a) small initial population of mixed cancer cells entails lobular pattern formation, b) the cell size plays a crucial role in cancer growth and propagation, c) the bigger cell size and the higher the number of the bigger cells (i.e., the higher proliferation rate of these cells and the larger their number in the initial population of cancer line), the smaller the final population of the mixed culture, d) increasing the number of cells not necessarily comes at the cost of the expansion of space occupied by them, consequently - lack of increase in the macroscopic size of a tumor does not mean lack of cell proliferation, e) the smaller cells seem to have an advantage under overcrowded conditions.

Naturally, all indications and suggestions included in this paper are based on in silico experiments and the simplified model. However, the results suggest a certain hypothesis of tumor growth that may be useful for explaining the outcome of some in vivo experiments and clinical data. The development and verification of theories proposed in this work may, as a consequence, lead to specific therapeutic measures. Therefore, the mixed cancer culture model can be a valuable tool for researchers, offering a promising direction for further studies and encouraging them to re-examine the existing data from the new perspective.

\section{Conflict of interests}

The authors have no conflict of interests to disclose.

\section{Acknowledgement}

We are deeply grateful to the reviewers for their contribution to improve this paper.

\section{REFERENCES}

Adamatzky A (2010) Game of life cellular automata. Springer, London. Adamatzky A (2018) Cellular Automata. Springer US, New York.

Al-Brahim N, Salama S (2005) Malignant melanoma with osteoclastlike giant cells: an unusual host response: immunohistochemical and ultrastructural study of three cases and literature review. $\mathrm{Am}$. J. Dermatopathol. 27: 126-129. https://doi.org/10.1097/00000372200504000-00007

Alemani D, Pappalardo F, Pennisi M, Motta S, Brusic V (2012) Combining cellular automata and Lattice Boltzmann method to model multiscale avascular tumor growth coupled with nutrient diffusion and immune competition. J. Immunol. Methods. 376: 55-68. https:// doi.org/10.1016/j.jim.2011.11.009

Alizadeh AA, Aranda V, Bardelli A, Blanpain C, Bock C, Borowski C, Caldas C, Califano A, Doherty M, Elsner M, Esteller M, Fitzgerald R, Korbel JO, Lichter P, Mason CE, Navin N, Pe'er D, Polyak K, Roberts CWM, Siu L, Snyder A, Stower H, Swanton C, Verhaak RGW, Zenklusen JC, Zuber J, Zucman-Rossi J (2015) Toward understanding and exploiting tumor heterogeneity. Nat. Med. 21: 846853. https://doi.org/10.1038/nm.3915

Ascolani G, Liò P (2019) Modeling breast cancer progression to bone: how driver mutation order and metabolism matter. BMC. Med. Genomics. 12: 106. https://doi.org/10.1186/s12920-019-0541-4 10.1186/s12920-019-0541-4

Asioli S, Righi A, Volante M, Chiusa L, Lloyd RV, Bussolati G (2014) Cell size as a prognostic factor in oncocytic poorly differentiated carcinomas of the thyroid. Hum. Pathol. 45: 1489-1495. https://doi. org/10.1016/j.humpath.2014.02.027

Baer RM, Martinez HM (1974) Automata and biology. Annu. Rev. Biophys. Bioeng. 3: 255-291. https://doi.org/10.1146/annurev. bb.03.060174.001351

Bao Q, Yu S, Yu X (2020) Collision tumor of meningioma and metastatic renal clear cell carcinoma: a case report. Br. J. Neurosurg. Apr 16: 1-3. https://doi.org/10.1080/02688697.2020.1751068

Bassukas ID, Maurer-Schultze B (1988) The recursion formula of the Gompertz function: a simple method for the estimation and comparison of tumor growth curves. Growth. Dev. Aging. 52: 113-122

Bunimovich-Mendrazitsky S, Pisarev V, Kashdan E (2015) Modeling and simulation of a low-grade urinary bladder carcinoma. Com- put. Biol. Med. 58: 118-129. https://doi.org/10.1016/j.compbiomed.2014.12.022

Burrell RA, McGranahan N, Bartek J, Swanton C (2013) The causes and consequences of genetic heterogeneity in cancer evolution. $\mathrm{Na}$ ture. 501: 338-345. https://doi.org/10.1038/nature12625

Castro MA, Klamt F, Grieneisen VA, Grivicich I, Moreira JC (2003) Gompertzian growth pattern correlated with phenotypic organization of colon carcinoma, malignant glioma and non-small cell lung carcinoma cell lines. Cell. Prolif. 36: 65-73. https://doi.org/10.1046/ j.1365-2184.2003.00259.x

Chen Q, Mynett AE (2003) Effects of cell size and configuration in cellular automata based prey - predator modelling. Simul. Model. Pract. Th. 11: 609-625. https://doi.org/10.1016/j.simpat.2003.08.006

Deutsch A, Dormann S (2017) Cellular Automaton Modeling of Biological Pattern Formation. Birkhäuser, New York. https://doi. org/10.1007/978-1-4899-7980-3

Deutsch A, Moreira J (2002) Cellular automaton models of tumor development: A critical review. Advs. Complex. Syst. 05: 247-267. https://doi.org/10.1142/S0219525902000572

Förnvik $\mathrm{D}$, Lång $\mathrm{K}$, Andersson $\mathrm{I}$, Dustler $\mathrm{M}$, Borgquist $\mathrm{S}$, Timberg $\mathrm{P}$ (2016) Estimates of breast cancer growth rate from mammograms and its relation to tumour characteristics. Radiat. Prot. Dosimetry. 169: 151-157. https://doi.org/10.1093/rpd/ncv417

Gardner M (1970) Mathematical Games. The fantastic combinations of John Conway's new solitaire game "life". Sci. Am. 223: 120-123

Gerlinger M, Rowan AJ, Horswell S, Math M, Larkin J, Endesfelder D, Gronroos E, Martinez P, Matthews N, Stewart A, Tarpey P, Varela I, Phillimore B, Begum S, McDonald NQ, Butler A, Jones D, Raine K, Latimer C, Santos CR, Nohadani M, Eklund AC, Spencer-Dene B, Clark G, Pickering L, Stamp G, Gore M, Szallasi Z, Downward J, Futreal PA, Swanton C (2012) Intratumor heterogeneity and branched evolution revealed by multiregion sequencing. N. Engl. J. Med. 366: 883-892. https://doi.org/10.1056/NEJMoa1113205

Gompertz B (1825) On the nature of the function expressive of the law of human mortality, and on a new mode of determining the value of life contingencies. Philos. T. S. Soc. Lond. 115: 513-583

Graner F, Glazier JA (1992) Simulation of biological cell sorting using a two-dimensional extended Potts model. Phys. Rev. Lett. 69: 20132016. https://doi.org/10.1103/PhysRevLett.69.2013

Greaves M, Maley CC (2012) Clonal evolution in cancer. Nature. 481: 306-313. https://doi.org/10.1038/nature10762

Grichnik JM, Burch JA, Schulteis RD, Shan S, Liu J, Darrow TL, Vervaert CE, Seigler HF (2006) Melanoma, a tumor based on a mutant stem cell. J. Invest. Dermatol. 126: 142-153. https://doi.org/10.1038/ sj.jid. 5700017

Hadeler K-P, Müller J (2018) Cellular Automata: Analysis and Applications. Springer International Publishing, Cham.

Hannig J, Schäfer H, Ackermann J, Hebel M, Schäfer T, Döring C, Hartmann S, Hansmann ML, Koch I (2020) Bioinformatics analysis of whole slide images reveals significant neighborhood preferences of tumor cells in Hodgkin lymphoma. PLoS. Comput. Biol. 16: e1007516. https://doi.org/10.1371/journal.pcbi.1007516

Hobbs MM, Geers TE, Brown TS, Malone JC (2020) Triple collision tumor comprising Merkel cell carcinoma with an unusual immunophenotype, squamous cell carcinoma in situ, and basal cell carcinoma. J. Cutan. Pathol. 47: 764-767. https://doi.org/10.1111/ cup. 13698

Junttila MR, de Sauvage FJ (2013) Influence of tumour micro-environment heterogeneity on therapeutic response. Nature 501: 346-354. https://doi.org/10.1038/nature12626

Karsch-Bluman A, Feiglin A, Arbib E, Stern T, Shoval H, Schwob $\mathrm{O}$, Berger M, Benny O (2019) Tissue necrosis and its role in cancer progression. Oncogene. 38: 1920-1935. https://doi.org/10.1038/ s41388-018-0555-y

Kiuru M, Tartar DM, Qi L, Chen D, Yu L, Konia T, McPherson JD, Murphy WJ, Fung MA (2018) Improving classification of melanocytic nevi: Association of BRAF V600E expression with distinct histomorphologic features. J. Am. Acad. Dermatol. 79: 221-229. https://doi.org/10.1016/j.jaad.2018.03.052

Kroemer G, Perfettini JL (2014) Entosis, a key player in cancer cell competition. Cell. Res. 24: 1280-1281. https://doi.org/10.1038/ cr.2014.133

Kumar S, Kulkarni R, Sen S (2016) Cell motility and ECM proteolysis regulate tumor growth and tumor relapse by altering the fraction of cancer stem cells and their spatial scattering. Phys. Biol. 13: 036001. https://doi.org/10.1088/1478-3975/13/3/036001

Kurimoto T, Ogawa K, Koga K, Ishida E, Mitsui Y, Nomi K, Miyagawa F, Shinkuma S, Asada H (2020) Apocrine mixed tumor of the skin with panfollicular differentiation: A rare case report with immunohistochemical evaluation. J. Dermatol. Aug 04: e408-e410 .https://doi.org/10.1111/1346-8138.15539

Li JF, Lowengrub J (2014) The effects of cell compressibility, motility and contact inhibition on the growth of tumor cell clusters using the Cellular Potts Model. J. Theor. Biol. 343: 79-91. https://doi. org/10.1016/j.jtbi.2013.10.008 
Li Q, Rycaj K, Chen X, Tang DG (2015) Cancer stem cells and cell size: A causal link. Semin. Cancer. Biol. 35: 191-199. https://doi. org/10.1016/j.semcancer.2015.07.002

Lyons SM, Alizadeh E, Mannheimer J, Schuamberg K, Castle J, Schroder B, Turk P, Thamm D, Prasad A (2016) Changes in cell shape are correlated with metastatic potential in murine and human osteosarcomas. Biol. Open. 5: 289-299. https://doi.org/10.1242/ bio.013409

Malik AA, Wennberg B, Gerlee P (2020) The impact of elastic deformations of the extracellular matrix on cell migration. B. Math. Biol. 82: 49. https://doi.org/10.1007/s11538-020-00721-2

Matsiaka OM, Baker RE, Simpson MJ (2019) Continuum descriptions of spatial spreading for heterogeneous cell populations: Theory and experiment. J. Theor. Biol. 482: 109997. https://doi.org/10.1016/j. itbi.2019.109997

McGranahan N, Swanton C (2017) Clonal heterogeneity and tumor evolution: past, present, and the future. Cell. 168: 613-628. https:// doi.org/10.1016/j.cell.2017.01.018

Meacham CE, Morrison SJ (2013) Tumour heterogeneity and cancer cell plasticity. Nature. 501: 328-337. https://doi.org/10.1038/nature12624

Michalinos A, Constantinidou A, Kontos M (2015) Gastric collision tumors: an insight into their origin and clinical significance. Gastroenterol. Res. Pract. 2015: 314158. https://doi.org/10.1155/2015/314158

Mitchell M (2019) Artificial intelligence: a guide for thinking humans. Farrar, Straus, Giroux/MacMillan (US), New York.

Mizuta H, Namikawa K, Takahashi A, Ogata D, Muto Y, Jinnai S, Nakama K, Tsutsui K, Yamazaki N (2020) The first case of a collision tumor of melanotrichoblastoma and seborrheic keratosis. Int. J. Dermatol. https://doi.org/10.1111/ijd.15042

Monteagudo Á, Santos J (2015) Treatment analysis in a cancer stem cell context using a tumor growth model based on cellular automata. PLoS. One. 10: e0132306. https://doi.org/10.1371/journal. pone.0132306

Neumann JV, Burks AW (1966) Theory of Self-Reproducing Automata. University of Illinois Press, Urbana.

Ohata C (2018) Hyaline cell-rich apocrine mixed tumor with cytologic atypia. Dermatopathology. 5: 108-112. https://doi org/10.1159/000492668

Palmari J, Lafon B, Martin PM, Dussert C (1997) Topographical analysis of spatial patterns generated by a cellular automaton model of the proliferation of a cancer cell line in vitro. Anal. Cell. Pathol. 14: 183028. https://doi.org/10.1155/1997/183028

Park JA, Atia L, Mitchel JA, Fredberg JJ, Butler JP (2016) Collective migration and cell jamming in asthma, cancer and development. $J$. Cell. Sci. 129: 3375-3383. https://doi.org/10.1242/jcs.187922

Picco N, Gatenby RA, Anderson ARA (2017) Stem cell plasticity and niche dynamics in cancer progression. IEEE. Trans. Biomed. Eng. 64: 528-537. https://doi.org/10.1109/TBME.2016.2607183

Rosai J (2011) Rosai and Ackerman's Surgical Pathology 10e. Elsevier, India

Ruan B, Niu Z, Jiang X, Li Z, Tai Y, Huang H, Sun Q (2019) High frequency of cell-in-cell formation in heterogeneous human breast cancer tissue in a patient with poor prognosis: a case report and literature review. Front. Oncol. 9: 1444. https://doi.org/10.3389/ fonc. 2019.01444

Saad ESA, Lam JSY, Al-Khan AA, Tayebi M, Day MJ, Richardson SJ, Danks JA (2019) A comparative review of mixed mammary tumors in mammals. J. Mammary. Gland. Biol. Neoplasia. 24: 125-137. https://doi.org/10.1007/s10911-018-9422-2

Sarna M, Zadlo A, Czuba-Pelech B, Urbańska K (2018) Nanomechanical phenotype of melanoma cells depends solely on the amount of endogenous pigment in the cells. Int. J. Mol. Sci. 19: 607. https:// doi.org/10.3390/ijms19020607

Sastre-Garau X, Genin P, Rousseau A, Al Ghuzlan A, Nicolas A, Freneaux P, Rosty C, Sigal-Zafrani B, Couturier J, Thiery JP, Magdelenat H, Vincent-Salomon A (2004) Increased cell size and Akt activation in HER-2/neu-overexpressing invasive ductal carcinoma of the breast. Histopathology. 45: 142-147. https://doi.org/10.1111/ j.1365-2559.2004.01899.x
Schmoller KM (2017) The phenomenology of cell size control. Curr. Opin. Cell. Biol. 49: 53-58. https://doi.org/10.1016/j.ceb.2017.11.011 Seifert G, Donath K (1996) Hybrid tumours of salivary glands. Definition and classification of five rare cases. Eur. J. Cancer. B. Oral. Oncol. 32B: 251-259. https://doi.org/10.1016/0964-1955(95)00059-3 Shirinifard A, Gens JS, Zaitlen BL, Poplawski NJ, Swat M, Glazier JA (2009) 3D multi-cell simulation of tumor growth and angiogenesis. PLoS. One. 4: e7190. https://doi.org/10.1371/journal.pone.0007190

Sporn MB (1996) The war on cancer. Lancet. 347: 1377-1381. https:// doi.org/10.1016/s0140-6736(96)91015-6

Stanta G, Bonin S (2018) Overview on clinical relevance of intratumor heterogeneity. Front. Med. 5: 85. https://doi.org/10.3389/ fmed.2018.00085

Steenbeek SC, Pham TV, de Ligt J, Zomer A, Knol JC, Piersma SR, Schelfhorst T, Huisjes R, Schiffelers RM, Cuppen E, Jimenez CR, van Rheenen J (2018) Cancer cells copy migratory behavior and exchange signaling networks via extracellular vesicles. EMBO. J. 37: 10.15252 /embj.201798357

Sterz H, Kendler M, Simon JC, Ziemer M (2019) Maligner kollisionstumor der haut: melanom, kutanes plattenepithelkarzinom und basalzellkarzinom. Pathologe. 40: 534-538. https://doi.org/10.1007/ s00292-019-0622-3

Szabo A, Merks RM (2013) Cellular potts modeling of tumor growth, tumor invasion, and tumor evolution. Front. Oncol. 3: 87. https:// doi.org/10.3389/fonc. 2013.00087

Talkington A, Durrett R (2015) Estimating tumor growth rates in vivo. Bull. Math. Biol. 77: 1934-1954. https://doi.org/10.1007/s11538015-0110-8

Tjørve KMC, Tjørve E (2017) The use of Gompertz models in growth analyses, and new Gompertz-model approach: An addition to the Unified-Richards family. PLoS. One. 12: e0178691. https://doi. org/10.1371/journal.pone.0178691

Turajlic S, Sottoriva A, Graham T, Swanton C (2019) Resolving genetic heterogeneity in cancer. Nat. Rev. Genet. 20: 404-416. https://doi. org/10.1038/s41576-019-0114-6

Tzedakis G, Grekas G, Tzamali E, Marias K, Sakkalis V (2014) The importance of grid size and boundary conditions in discrete tumor growth modeling. Proceedings of the 2014 6th International Advanced Research Workshop on In Silico Oncology and Cancer Investigation - The CHIC Project Workshop (IARWISOCI). https://doi.org/10.1109/ IARWISOCI.2014.7034635

Tzedakis G, Tzamali E, Marias K, Sakkalis V (2015) The importance of neighborhood scheme selection in agent-based tumor growth modeling. Cancer. Inform. 14: 67-81. https://doi.org/10.4137/CIN. S19343

Wcisło R, Dzwinel W, Yuen DA, Dudek AZ (2009) A 3-D model of tumor progression based on complex automata driven by particle dynamics. J. Mol. Model. 15: 1517-1539. https://doi.org/10.1007/ s00894-009-0511-4

Wcisło R, Gosztyła P, Dzwinel W (2010) N-body parallel model of tumor proliferation. Proceedings of the 2010 Summer Computer Simulation Conference: SummerSim. 160-167

Wolfram S (1986) Theory and applications of cellular automata: including selected papers, 1983-1986. World Scientific Pub, Singapore.

Wong YP, Affandi KA, Tan GC, Muhammad R (2017) Metastasis within a metastasis to the thyroid: A rare phenomenon. Indian. J. Pathol. Microbiol. 60: 430-432. https://doi.org/10.4103/IJPM. IJPM_287_16

Wu P-H, Phillip JM, Khatau SB, Chen W-C, Stirman J, Rosseel S, Tschudi K, Van Patten J, Wong M, Gupta S, Baras AS, Leek JT, Maitra A, Wirtz D (2015) Evolution of cellular morpho-phenotypes in cancer metastasis. Sci. Rep-UK. 5: 18437. https://doi. org $/ 10.1038 /$ srep 18437

Xu J, Jiang X, Li H, Arlinghaus LR, McKinley ET, Devan SP, Hardy BM, Xie J, Kang H, Chakravarthy AB, Gore JC (2020) Magnetic resonance imaging of mean cell size in human breast tumors. Magn. Reson. Med. 83: 2002-2014. https://doi.org/10.1002/mrm.28056 